\title{
Effects of space environment on embryonic growth up to hatching of salamander eggs fertilized and developed during orbital flights
}

\author{
Lydie Gualandris-Parisot ${ }^{1}$, David Husson ${ }^{1}$, Alain Bautz ${ }^{2}$, Danielle Durand ${ }^{2}$, Paulette Kan ${ }^{1}$, Christian Aimar ${ }^{2}$, \\ Hervé Membre ${ }^{2}$, Anne-Marie Duprat ${ }^{1}$, Christian Dournon ${ }^{2 *}$ \\ ${ }^{1}$ Center of Developmental Biology UMR 5547 CNRS- Paul Sabatier University, 118 Route de Narbonne, 31062 \\ Toulouse cedex, France. \\ ${ }^{2}$ Laboratory of Experimental Biology-Immunology, EA 3442: Genetic, Signaling, Differentiation, Henri Poincaré \\ University -Nancy-1, B.P. 239, 54506 Vandoeuvre-les-Nancy cedex, France.
}

\begin{abstract}
In vertebrates, only few experiments have been performed in microgravity to study the embryonic development from fertilization. To date, these concern only amphibian and fish. We report here a study on the embryonic development of Pleurodeles waltl (urodele amphibian) eggs oviposited in microgravity. The experiment was performed twice on board the Mir space station and the data obtained included video recording and morphological, histological and immunocytological analyses.

The data confirm that the microgravity conditions have effects during the embryonic period, particularly during cleavage and neurulation, inducing irregular segmentation and abnormal closure of the neural tube. Moreover, we observed several abnormalities hither to undescribed corresponding to cortical cytoplasm movements, a decrease of cell adhesion and a loss of cells. These abnormalities were temporary and subsequently reversible. The young larvae that hatched during the flight displayed normal morphology and swimming behavior after landing. The results obtained in the urodele Pleurodeles waltl are in accordance with those observed earlier in the anuran Xenopus laevis and in the fish Oryzias latipes.
\end{abstract}

Key words; ChAT, cleavage, neurulation, urodele, weightlessness.

\section{Introduction}

In vertebrates, the only experiments to date on fertilization and embryonic development in microgravity $(\mu \mathrm{G})$ have been performed with amphibian and fish. Although dependent on experimental conditions, early development was perturbed.

In anurans, whose fertilization is external and monospermatic, the authors relied on artificial fertilization. In 1968, during the 11-hour Gemini mission, apparently normal cleavage stage Rana pipiens embryos were obtained from eggs fertilized on the launching pad (Young \& Tremor 1968). Working on Xenopus laevis and using automatic hardware, Ubbels et al. (1989) first obtained artificial fertilization and the beginning of development in microgravity, on board sounding rockets. Under the same conditions, and then on board American space shuttles, she described abnormal blastulae and gastrulae with a thick blastocoel roof (Ubbels et al. 1994; Ubbels 1997). Souza et al. (1995) obtained fertilization and development of Xenopus tadpoles on board a space shuttle. Oocytes were fertilized in vitro with spermatozoa previously prepared

Original paper

Received November 30, 2001

Accepted March 1, 2002

Address for correspondence: Christian Dournon Laboratory of Experimental Biology-Immunology, EA 3442: Genetic, Signaling, Differentiation, Henri Poincaré University -Nancy-1, B.P. 239, 54506 Vandoeuvre-les-Nancy cedex, France.

E-mail: Christian.Dournon@scbiol.uhp-nancy.fr on the ground. Ovulation of oocytes was induced by hormone injection during the flight, and fertilized eggs were then put on plates in microgravity or in a centrifuge permanently rotating at $1 \mathrm{G}$. In flight, embryos were fixed for histological study or kept alive for rearing. Two-cell $\mu \mathrm{G}$-embryos, gastrulae, neurulae and swimming tadpoles all appeared externally normal. However, the young $\mu \mathrm{G}$ gastrulae had a thicker blastocoel roof than those developing under $1 \mathrm{G}$ conditions (Black et al. 1996).

In urodeles, the so-called AstroNewt experiments that used Cynops pyrrhogaster were performed on board the American shuttle Columbia on the Second International Microgravity Laboratory (IML-2) in 1994 and on board a Japanese Space Flyer Unit put in orbit in 1995 and retrieved by an U.S.A. Space Shuttle in 1996. The aim of these experiments was to study the development of urodele eggs laid by preinseminated females automatically injected or hormonally treated to trigger ovulation in microgravity conditions. Some females died during the flights but others laid about 71 eggs that developed into embryos judged as normal by examination of video images taken in orbit (Mogami et al. 1996; Yamashita et al. 2001).

In fish, Ijiri $(1995,1997)$ obtained the reproduction of couples of Oryzias latipes and development of embryos under microgravity conditions. Embryonic development and behavior of the post-landing lineages seemed normal.

During the 1990-1999 decade, research into amphibian development in space was particularly active for two main reasons; fist, amphibians are a popular model in embryology and developmental biology, second, they can be reared on board space vehicles more easily than 
mammals. Our experiments were performed with Pleurodeles waltl. In comparison with Xenopus laevis, the interest of $P$. waltl is that the embryonic and larval development rates are slow and thereby facilitating analysis of various developmental stages. For example, at $18^{\circ} \mathrm{C}$, the hatching stage is reached after 2 and 12 days in Xenopus and Pleurodeles, respectively. The goal of our project was to answer three questions. Can fertilization occur normally on board a space station? If so, is subsequent embryonic development normal in microgravity? The further development and reproduction be normal or not after return to Earth?

We performed two duplicate experiments on board the Mir space station. Control experiments were synchronously performed in a laboratory on the ground using the same hardware as that on board Mir. The first experiment took place during the 1996 Cassiopeia mission from August 17 to September 2, and the second one during the 1998 Pegasus mission from January 29 to February 19. In our experiments named 'FERTILE', the spermatozoa were preserved in the cloacal pelvic glands of preinseminated $P$. walt females. During egg laying, they crossed the jelly coat and penetrated the oocytes in a natural manner. In a previous publication, we demonstrated that the development obtained on board Mir was the consequence authentic fertilization and not of parthenogenesis or gynogenesis (Aimar et al. 2000). We also showed that the subsequent larval development, metamorphosis and reproduction of animals oviposited and developed up to hatching stages in microgravity occurred normally (Dournon et al. 2001).

The aim of the present paper is to present statistically significant data concerning the embryonic development that occurred after fertilization obtained during space flights, up to the hatching stage. While confirming previous results, we observed abnormalities that had not been described earlier.

\section{Material and Methods}

Animals; All the Pleurodeles walt (urodele amphibian) derived from the standard strain of the laboratory. The Cassiopeia mission took place outside the natural reproductive season of this salamander. Consequently, to keep alive the greatest possible number of spermatozoa in the cloacal glands after a natural mating, the inseminated females were maintained at $8^{\circ} \mathrm{C}$ for $12-16$ weeks before the launch. The Pegasus mission occurred during the reproductive period. The inseminated females were maintained until the launch at room temperature $\left(13-16^{\circ} \mathrm{C}\right)$ for 2-8 weeks after a natural mating. Embryos and larvae were staged according to the table of development of Gallien and Durocher (1957). The animals were treated according to the principles expressed in the Declaration of Helsinki and the Council Directive of the European Communities on the Protection of Animals Used for Experimental and Other Scientific Purposes (L358/1, November 24, 1980).
The Fertile instrument; An instrument named 'Fertile' was developed in collaboration with the French space agency (CNES) and the French manufacturer COMAT (Husson et al. 2001). It was an incubator set at $18 \pm 1{ }^{\circ} \mathrm{C}$, connected to an air circulation system and containing a) a video camera to film the development of $\mu \mathrm{G}$-embryos, $b$ ) three egg-laying boxes and two trays for the storage of egg-boxes placed in microgravity. Some egg-boxes included a capsule of fixative liquid, others were used to keep embryos alive. A 'delrim' grid separated the $14.85 \mathrm{ml}$ water and egg compartment and the $17.93 \mathrm{ml}$ air compartment. c) a centrifuge running at $1 \mathrm{G}$ on board Mir for the storage of egg-boxes at $18 \pm 1{ }^{\circ} \mathrm{C}$. The arm of the centrifuge is $116 \mathrm{~mm}$ long (from the axis to the mid-central point in the egg box). d) nine radio-dosimeters.

Measurement of radiation; During the 17-day Cassiopeia space flight mission, the cumulated dose of cosmic and solar radiations was $350 \pm 6 \mathrm{mrad}$ and $10 \pm 1$ mrad on board Mir and on earth, respectively. During the 22-day Pegasus space flight mission, the dose was $457 \pm 7$ mrad and $15 \pm 1 \mathrm{mrad}$ on board Mir and on ground, respectively. The eggs and the embryos were less exposed because they were fertilized and developed after the beginning of the flight. On board Mir, the first embryos had the remaining 12 of 16 and 13 of 21 days, respectively, of development in microgravity and exposure to space radiations.

General protocol; For each launch, a thermally controlled container (CTA, in French: 'Container de Transport Aller') was used for the transportation of six $P$. walt females in three boxes toward the Mir station. The CTA was set at $18 \pm 2^{\circ} \mathrm{C}$, and an air pomp ventilated $(0.2$ liter/min) the three boxes of transport. In each box, two adults were maintained without free water, but a damp toweling covered the two largest internal surfaces and moisturized their skin. The trip toward the Mir station was two days long. During this period, the crew accessed to the animals. In flight, the protocol consisted in obtaining laying of fertilized eggs in two Fertile instruments, one on board Mir and the other in the ground laboratory. Egg laying was induced by an injection of $1.5 \mu l$ Luteinising HormoneReleasing Hormone (LH-RH; Sigma, St Louis, MO, USA; $10 \mu \mathrm{g} / \mathrm{ml}$ in physiologic medium) into females that have been previously inseminated on the ground (Aimar et al. 2000). All the eggs were oviposited in microgravity, collected just after laying and distributed in twin boxes (about 20 eggs per box) with scissors and forceps. One box was stored on trays in ambient gravity and the other was placed in the centrifuge. The eggs were randomly placed in the centrifuge 1-4 hrs after laying. Most eggs of the twin batches were fixed at different times of the embryonic development. The others were kept alive. Due to the absence of a freezer on board Mir and of electricity for the experiments during the return of the Soyuz vehicles to Earth, we could not perform molecular analysis of deepfrozen embryos. For the return trip, the biological materials 
were on board the Soyuz at the most one day. Up to dedocking, the temperature increased progressively from 18 to $22^{\circ} \mathrm{C}$. From dedocking up to landing, the trip was about six hours long and the temperature increased from 22 to $25^{\circ} \mathrm{C}$. After landing, the living animals were put at $18{ }^{\circ} \mathrm{C}$. A similar profile was synchronously applied but the control experiments performed in ground laboratory were two days shifted. Effects of vibrations and shocks have been previously tested on animals and materials (Husson et al. 2001).

Fixing of the embryos; For the two space missions on board MIR, embryos in their jelly coat developed in hermetic egg-boxes at $18{ }^{\circ} \mathrm{C}$ in $8 \mathrm{ml}$ of sterile Steinberg rearing medium (Dournon et al. 2001). The formaldehyde fixative was contained in capsules located in the egg-boxes. A manual action distributed $500 \mu \mathrm{l}$ of a $37 \%$ formaldehyde solution to give a final concentration of $2.2 \%$. Embryos were kept in the fixative up to the end of the flights, and then transferred to a $3.5 \%$ formaldehyde solution. The same protocol was applied to the ground control embryos.

Histological analyses and immunolocalizations; After landing, all the fixed embryos were photographed. For histological examinations, some were dehydrated in ethanol, embedded in paraffin, cut into $8 \mu \mathrm{m}$ sections, and stained with safranin methyl blue orange $\mathrm{G}$ or hemalum eosin. To perform immunolocalizations, other embryos were incubated in increasing concentrations of sucrose solutions $(5,10,15,20,25$ and $30 \%)$, embedded in Cryomount (Micron), frozen in isopentane in liquid nitrogen and cut into $14 \mu \mathrm{m}$ sections. Different primary antibodies were used to compare the differentiation of organs in $\mu \mathrm{G}$ - and 1G-embryos: anti-GFAP, a polyclonal antibody directed against a glial fibrillary acidic protein (Dakoppats); anti-NC1, a monoclonal antibody directed against a neuronal cell membrane glycoprotein and used as a specific neuronal cell marker in Pleurodeles, (SaintJeannet et al. 1990); anti-MF20, a monoclonal antibody directed against a sarcomere myosin of striated muscle (Hybridoma bank); anti-GABA, a polyclonal antibody directed against gamma aminobutyric acid-containing neurons (Pituello et al. 1989). Two fluorescein (FITC)- or rhodamine (TRITC)-conjugated secondary antibodies were applied using standard protocols. The immunolocalizations were performed with confocal (LSM 410, Zeiss) or epifluorescence (Leitz Dialux 20) microscopy.

Choline acetyltransferase (ChAT) assays; Live hatching larvae were cooled 8-10 hrs after the landing of each space mission. They were 8.5 and 10.5-days old, respectively. ChAT activity was measured in the presence of tritiated acetyl Coenzyme A (5.8 mCi/mol, Amersham) using a previously described method (Duprat et al. 1985). The results were expressed as $\mathrm{pmol} / \mathrm{min} / \mathrm{embryo.}$

Statistical analysis; To compare both values and percentages of embryos, we used the $\chi^{2}$ test with the Yates correction $\left(\chi_{c}^{2}\right)$. The limit of significance for all the tests was 3.841 for 1 degree of freedom and $\alpha=0.05$. To compare the thickness of the blastocoel roof, Student's t test was used. To compare the ChAT activity, we used the MannWhitney test.

\section{Results}

1 - Embryos developed on board MIR and on the ground On board MIR, 10 out of 12 inseminated females, reared

Table 1 Embryos layed on board the Mir station or in the ground laboratory. At left, number (No) and percentage (\%) of developed embryos fixed in flight at different stages of development. At right, number (No) and percentage (\%) of embryos obtained alive after delivery of the samples on ground. Some embryos were used for histological analyses and ChAT assays

\begin{tabular}{|c|c|c|c|c|c|c|}
\hline & \multicolumn{3}{|c|}{ Embryos fixed during the flight } & \multicolumn{3}{|c|}{ Embryos kept alive during the flight } \\
\hline & $\begin{array}{l}\text { No of eggs } \\
\text { used to study } \\
\text { the embryonic } \\
\text { development }\end{array}$ & $\begin{array}{c}\text { No of } \\
\text { developed } \\
\text { and fixed } \\
\text { embryos }\end{array}$ & $\begin{array}{c}\% \text { of } \\
\text { developed } \\
\text { and fixed } \\
\text { embryos }\end{array}$ & $\begin{array}{l}\text { No of eggs } \\
\text { used to } \\
\text { obtained in } \\
\text { live embryos }\end{array}$ & $\begin{array}{l}\text { No of } \\
\text { embryos in } \\
\text { live after } \\
\text { landing }\end{array}$ & $\begin{array}{l}\% \text { of in live } \\
\text { embryos } \\
\text { after landing }\end{array}$ \\
\hline \multicolumn{7}{|l|}{ Cassiopeia mission } \\
\hline In $\mu \mathrm{G}$ on board MIR & 504 & 108 & 21.4 & 194 & 43 & 22.2 \\
\hline In $1 \mathrm{G}$ MIR centrifuge & 147 & 19 & 12.9 & 21 & 14 & 66.7 \\
\hline In $1 G$ on ground & 527 & 120 & 22.8 & 139 & 1 & 0.7 \\
\hline \multicolumn{7}{|l|}{ Pegasus mission } \\
\hline In $\mu \mathrm{G}$ on board MIR & 719 & 592 & 82.4 & 122 & 51 & 41.8 \\
\hline In $1 G$ MIR centrifuge & 173 & 150 & 86.7 & - & - & - \\
\hline In $1 \mathrm{G}$ on ground & 680 & 528 & 77.6 & 230 & 93 & 40.4 \\
\hline \multicolumn{7}{|l|}{ Total missions } \\
\hline In $\mu \mathrm{G}$ on board MIR & 1223 & 700 & 57.2 & 397 & 94 & 23.7 \\
\hline In 1G MIR centrifuge & 320 & 169 & 52.8 & 21 & 14 & 66.7 \\
\hline In $1 G$ on ground & 1207 & 648 & 53.7 & 369 & 94 & 25.5 \\
\hline
\end{tabular}




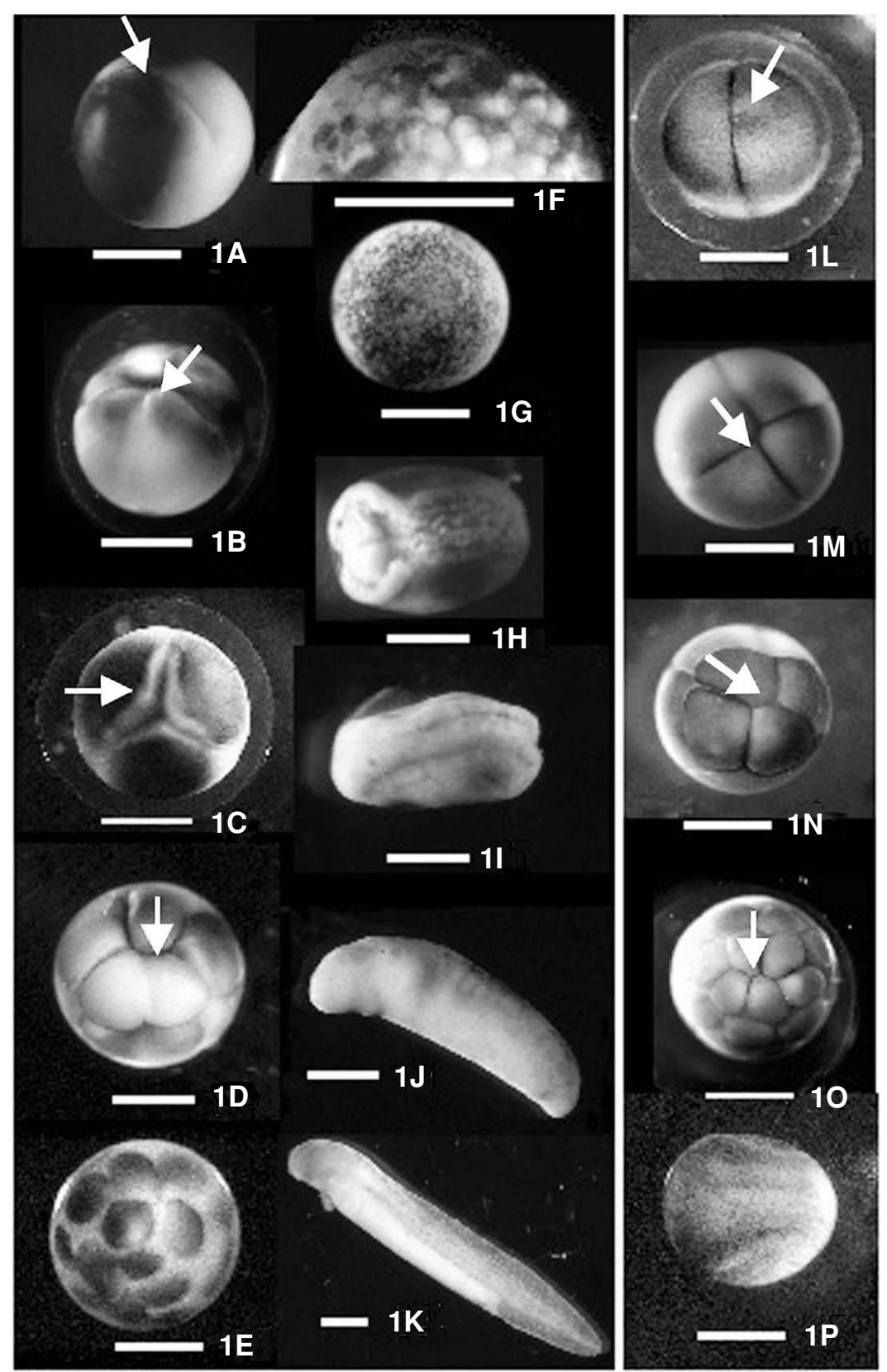

Fig. 1 A to J: $\mu$ G-embryos fertilized, developed and fixed on board MIR. $\mathbf{K}$ to $\mathbf{O}: 1 \mathrm{G}$ - ground control embryos. Arrows indicate the animal pole. A: beginning of the first cleavage. Abnormal pigmented area. B: beginning of the second cleavage. Abnormal pigmented area. Enlarged intercellular space. C: abnormal three-cell stage. D: Five blastomeres instead of 4 at the animal hemisphere. Enlarged intercellular space. E: morula stage. Yolk platelets between blastomeres. F: detail of a blastula. Showing detached cells. G: blastula at stage 7. H: neurula at stage 15 . Loss of neurectodermal cells. I: neurula at stage 20 . Neural tube not closed in the dorsal region. J: embryo at tail bud stage 25 . Normal aspect. K: embryo at stage 32 . Normal aspect. L: twocell embryo. M: four-cell embryo. $\mathbf{N}$ : eight-cell embryo. Four pigmented and four unpigmented cells of the animal and vegetative hemispheres, respectively. O: morula stage. P: neurula at stage 15 . Bar $=1 \mathrm{~mm}$.

at $18^{\circ} \mathrm{C}$, provided embryos, which developed in $\mu \mathrm{G}$ and in $1 \mathrm{G}$. Of 12 ground control females, 11 provided embryos that developed in $1 \mathrm{G}$. The percentage of development was defined as the number of developed embryos at the 2-cell stage or later stages divided by the total number of eggs.
The numbers and percentages of development of in-flight and on-ground embryos were similar for each space mission. The Cassiopeia mission took place outside the reproductive period, whereas the Pegasus mission occurred during the reproductive period and the percentage of development was therefore optimal (Table $1)$. The timing of development was established by observation of the fixed embryos, annotations of the crew at each fixation time and video recording.

\section{2 - Cleavage period}

This period includes stages 1 to 7 . Embryos at all these stages were obtained in flight.

Effects of microgravity on the inner cytoplasm of eggs. Sections of $\mu \mathrm{G}$-embryos at the beginning of cleavage were examined under light microscopy. In these eggs, yolk platelets were distributed along an animal pole-vegetal pole axis in a gradient of increasing size, the smallest ones laying at the animal pole, as in 1G-egg controls. No striking modification of the vitelline gradient was observed in the different replicates. In addition, the cortical cytoplasm underneath the cell membrane of $\mu \mathrm{G}$-eggs was yolk free and had the same constant thickness as that of $1 \mathrm{G}$-control eggs.

Cleavage. At the beginning of cleavage, three kinds of abnormalities were observed in $\mu \mathrm{G}$-embryos. A given embryo expressed one or several abnormalities and all possible combinations were observed (Fig. $1 \mathrm{~A}$ to $\mathrm{D}$ and $\mathrm{L}$ to $\mathrm{O}$; Table 2). The aspect and position of the pigmented animal area were modified and were unrelated to the orientation of the cleavage planes. This modification was observed in $34.4 \%, 13.0$ $\%$ and $11.9 \%$ of $\mu \mathrm{G}-, 1 \mathrm{G}$-on board and $1 \mathrm{G}$-ground embryos, respectively. The difference between $\mu \mathrm{G}$ - and $1 \mathrm{G}$-centrifuge embryos was not statistically significant $\left(\chi_{c}^{2} 3.694\right)$ but was significant between $\mu \mathrm{G}$ - and $1 \mathrm{G}$-ground embryos $\left(\chi_{\mathrm{c}}^{2}\right.$ 6.687). There was no difference between $1 \mathrm{G}$ centrifuge and $1 \mathrm{G}$-ground embryos $\left(\chi_{\mathrm{c}}^{2}\right.$ 0.005 ) (Table 2).

The cleavage was irregular. For example, three, five or seven cells were observed in the animal hemisphere. This was seen in $31.6 \%, 7.7 \%$ and $2.3 \%$ of $\mu \mathrm{G}-, 1 \mathrm{G}$-on board and $1 \mathrm{G}$-ground embryos, respectively. The difference between $\mu \mathrm{G}$ - and $1 \mathrm{G}$ centrifuge embryos was not statistically significant $\left(\chi_{\mathrm{c}}^{2}\right.$ 
Table 2 Number and percentage of abnormalities in analyzed embryos as a function of developmental stage.

\begin{tabular}{|c|c|c|c|c|c|c|}
\hline Period & & $\begin{array}{l}\mu \mathrm{G} \text {-embryos on } \\
\text { board MIR }\end{array}$ & $\begin{array}{l}\text { 1G-embryos } \\
\text { centrifuged } \\
\text { on board MIR }\end{array}$ & $\begin{array}{l}\text { 1G-ground } \\
\text { control } \\
\text { embryos }\end{array}$ & $\begin{array}{l}{ }^{*} \chi_{c}^{2} \text { test } \\
1,2,3\end{array}$ & $\begin{array}{c}\text { Student } \\
\mathrm{t} \text {-test }\end{array}$ \\
\hline \multirow{8}{*}{$\begin{array}{c}\text { Cleavage } \\
\text { Abnormalities } \\
\text { stages } 1 \text { to } 5\end{array}$} & $\begin{array}{c}\text { No of embryos } \\
\text { Abnormal pigmentation }\end{array}$ & 121 & 75 & 101 & & \\
\hline & No of cases & $10 / 29$ & $6 / 46$ & $12 / 101$ & & \\
\hline & $\begin{array}{c}\% \\
\text { Irregular cleavage }\end{array}$ & $34.4 \%$ & $13.0 \%$ & $11.9 \%$ & $\mathrm{~ns}, \mathrm{~s}, \mathrm{~ns}$ & \\
\hline & No of cases & $12 / 38$ & $1 / 13$ & $1 / 43$ & & \\
\hline & $\%$ & $31.6 \%$ & $7.7 \%$ & $2.3 \%$ & $\mathrm{~ns}, \mathrm{~s}, \mathrm{~ns}$ & \\
\hline & Enlarged intercellular space ${ }^{\circ}$ & & & & & \\
\hline & No of cases & $19 / 47$ & $3 / 28$ & $1 / 65$ & & \\
\hline & $\%$ & $40.4 \%$ & $10.7 \%$ & $1.5 \%$ & $\mathrm{~s}, \mathrm{~s}, \mathrm{~ns}$ & \\
\hline \multirow{3}{*}{$\begin{array}{l}\text { Normal embryos } \\
\text { stage } 7\end{array}$} & Blastocoel roof thickness & & & & & \\
\hline & No of cases & 16 & 24 & & & \\
\hline & $\mu m$ & $194.0 \pm 56.7$ & $196.7 \pm 82.7$ & & & ns \\
\hline \multirow{3}{*}{$\begin{array}{c}\text { Gastrulation } \\
\text { Abnormalities } \\
\text { stage } 8\end{array}$} & $\begin{array}{c}\text { No of embryos } \\
\text { Blastocoel roof thickness }\end{array}$ & 48 & 19 & 26 & & \\
\hline & No of cases & 28 & 8 & & & \\
\hline & $\mu \mathrm{m}$ & $202.1 \pm 36.2$ & $130.0 \pm 38.5$ & & & $\mathrm{~s}$ \\
\hline \multirow[t]{3}{*}{$\begin{array}{c}\text { Neurulation } \\
\text { Abnormalities } \\
\text { stages } 16 \text { to } 21\end{array}$} & $\begin{array}{c}\text { No of embryos } \\
\text { Incomplete neural tube } \\
\text { closure }\end{array}$ & 37 & 21 & 24 & & \\
\hline & No of cases & $13 / 16$ & $1 / 12$ & $0 / 10$ & & \\
\hline & $\%$ & $81 \%$ & $8 \%$ & $0 \%$ & $\mathrm{~s}, \mathrm{~s}, \mathrm{~ns}$ & \\
\hline $\begin{array}{c}\text { Tail bud } \\
\text { Abnormalities }\end{array}$ & $\begin{array}{l}\text { No of embryos } \\
\text { Small head }\end{array}$ & 63 & 54 & 32 & & \\
\hline \multirow[t]{5}{*}{ stages 22 to 36} & No of cases & $16 / 63$ & $10 / 54$ & $3 / 32$ & & \\
\hline & $\%$ & $25.4 \%$ & $18.5 \%$ & $9.4 \%$ & $\mathrm{~ns}, \mathrm{~ns}, \mathrm{~ns}$ & \\
\hline & $\begin{array}{c}\text { Ascite } \\
\text { Stages } 28 \text { to } 33 \text { only }\end{array}$ & & & & & \\
\hline & No of cases & $6 / 30$ & $4 / 19$ & $1 / 16$ & & \\
\hline & $\%$ & $20.0 \%$ & $21.1 \%$ & $6.2 \%$ & ns, ns, ns & \\
\hline Total num & ber of analyzed embryos & 269 & 169 & 183 & & \\
\hline
\end{tabular}

$* \chi_{c}^{2}$ test: 1 , difference between $\mu \mathrm{G}$ - and $1 \mathrm{G}$-embryos centrifuged on board MIR; 2 , difference between $\mu \mathrm{G}$ - and $1 \mathrm{G}$-embryos on ground; 3 , difference between 1G-embryos centrifuged on board MIR and 1G-ground control embryos (ns, no significant; s, significant). ${ }^{\circ}$ Sampling of embryos developed in egg boxes from one or both missions

1.777) but significant between $\mu \mathrm{G}$ - and $1 \mathrm{G}$-ground embryos $\left(\chi_{c}^{2} 10.728\right)$. There was no difference between $1 \mathrm{G}-$ centrifuge and $1 \mathrm{G}$-ground embryos $\left(\chi_{\mathrm{c}}^{2} 0.003\right)$.

The intercellular space was enlarged at the animal surface of the embryo, indicating a decrease of cell adhesion. This was observed in $40.4 \%, 10.7 \%$ and $1.5 \%$ of $\mu \mathrm{G}-, 1 \mathrm{G}-$ on board and $1 \mathrm{G}$-ground embryos, respectively (Figs. 1D and 2A). The differences were statistically significant between $\mu \mathrm{G}$ - and $1 \mathrm{G}$-centrifuge $\left(\chi_{c}^{2} 6.101\right)$ or $1 \mathrm{G}$-ground embryos $\left(\chi_{c}^{2} 25.706\right)$. There was no difference between $1 \mathrm{G}$-centrifuge and $1 \mathrm{G}$-ground embryos $\left(\chi_{\mathrm{c}}^{2}\right.$ 2.104).

At blastula stages, vitellus pellets were observed between the blastomeres of some $\mu \mathrm{G}$-embryos, suggesting a rupture of the membrane of inner cells of the vegetal hemisphere (Fig. 1E). Small cells of the periphery were detaching (Fig. 1F and G). The 1G-controls had no such an abnormality. Histological observations of embryos at stage 7 indicated that the blastocoel was located inside the animal hemisphere, as it was in control embryos. The roof of the blastocoel, made up of two layers of cells, had an identical thickness: $194.0 \pm 56.7$ and $196.7 \pm 82.7 \mu \mathrm{m}$ for the $\mu \mathrm{G}$ - and $1 \mathrm{G}$-blastulae (Student's t test not significant $\mathrm{p}$ $=0.90)$.

\section{3 - Gastrulation period}

This period encompasses stages 8 to 12 . Only embryos at stages 8 and 9 were obtained in flight. Histological observations showed that the blastocoel roof was thicker in $\mu \mathrm{G}$ - than in $1 \mathrm{G}$-gastrulae at stage $8,202.1 \pm 36.2$ and $130.0 \pm 38.5 \mu \mathrm{m}$, respectively (Student's t tests significant $\mathrm{p}=0.0008$ ). However, as in the case of blastula, the roof was always composed of two layers of weakly cohesive cells in $\mu \mathrm{G}$-embryos (not illustrated).

\section{4 - Organogenesis \\ Neurulation period}

This period encompasses stages 13 to 21 . Embryos at stages 16 to 21 were obtained in microgravity. All the $\mu \mathrm{G}-$ embryos without exception displayed normal bilateral symmetry. At stage $21,81.3 \%$ of the $\mu \mathrm{G}$-embryos showed an incomplete closure of the neural tube at the cephalic and trunk levels. During neural tube closure, cells were 

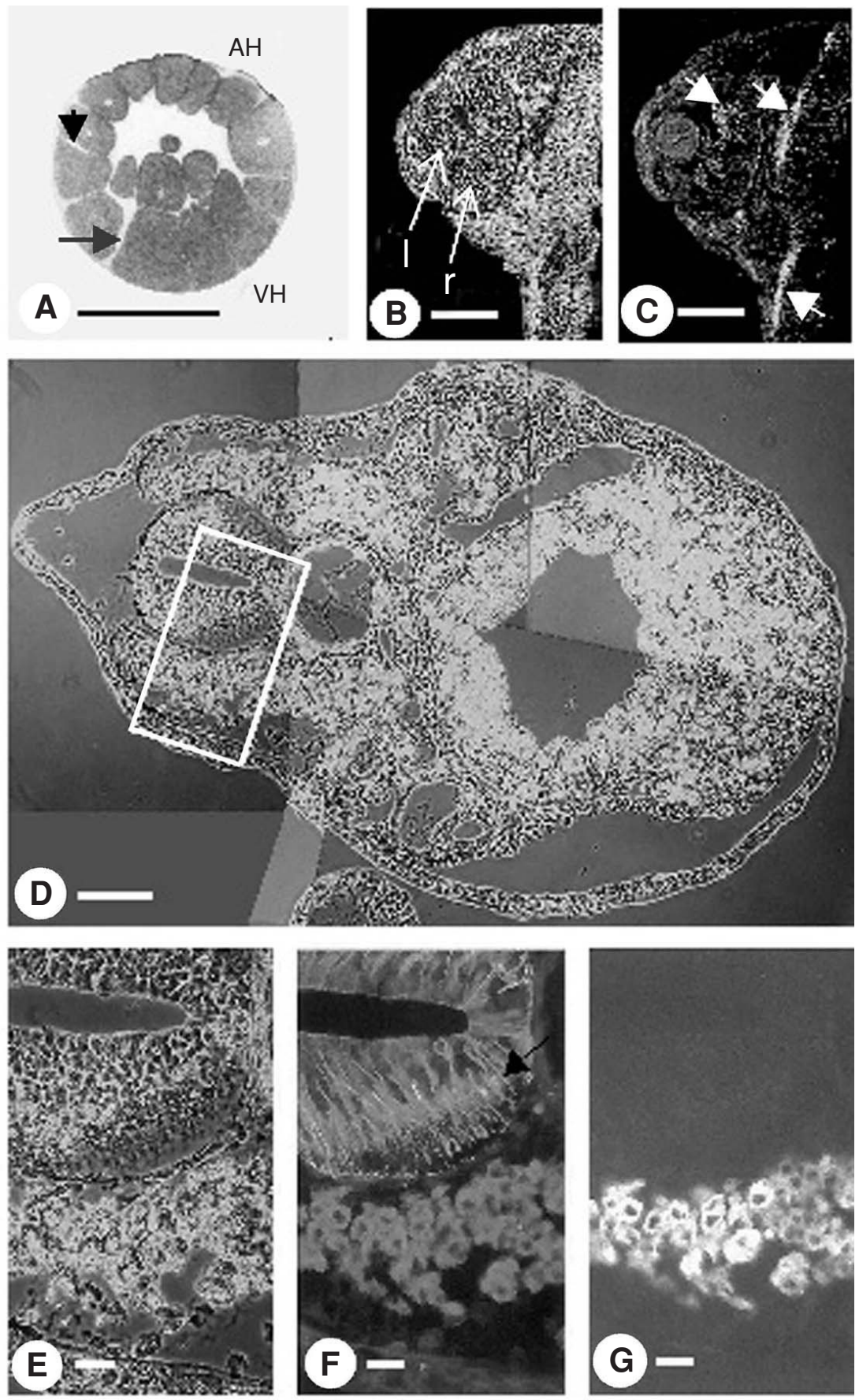

Fig. 2 A: para-meridian section of a $\mu \mathrm{G}$-embryo at the blastula stage. Arrows: enlarged intercellular space. AH: animal hemisphere, VH: vegetal hemisphere. B and C: successive transverse sections of the eye at the level of the diencephalon of $\mu \mathrm{G}$-embryo at stage 32 . B: phase contrast. 1: lens; r: retina. C: immunolocalization of neuronal cells with NC1 marker. Localization of NC1 in retina and white matter (arrows). D to G: successive transverse sections at the level of the gills in $\mu \mathrm{G}-$ embryo at stage 34. D: general view and E: detail, phase contrast. F: detail, radial glial cells detected with GFAP-TRICT antibodies. G: detail, somitic cells visualized by MF20-FITC antibodies. Bar $\mathbf{A}=1 \mathrm{~mm}$. Bar B, C, D = $250 \mu \mathrm{m}$. Bar $\mathbf{E}, \mathbf{F}, \mathbf{G}=50 \mu \mathrm{m}$. No particular difference was detected between $\mu \mathrm{G}$ - and $1 \mathrm{G}$-embryos (not illustrated).

shed from the neurectoderm and were observed outside the tube (Fig. 1H, I and P). In contrast, the cells of the epidermis that differentiated from ectoderm showed normal adhesion. In $1 \mathrm{G}$-embryos, only $8.3 \%$ of the $1 \mathrm{G}$-centrifuge and $0 \%$ of the $1 \mathrm{G}$-ground embryos exhibited an abnormal neurulation (Table $2)$. The differences were statistically significant between $\mu \mathrm{G}-$ and $1 \mathrm{G}$ centrifuge $\left(\chi_{c}^{2} 11.812\right)$ or $1 \mathrm{G}$-ground embryos $\left(\chi_{c}^{2} 13.162\right)$. There was no difference between 1G-centrifuge and $1 \mathrm{G}$-ground embryos $\left(\chi_{\mathrm{c}}^{2} 0.007\right)$.

In the course of development, the epidermal cells acquired cilia, the movement of which progressively induced a rotation of the embryos within the egg membranes. Under natural conditions, this movement was very slow and could only be observed by time-lapse video-recordings. Under microgravity conditions, video-movies confirmed that rotation began at the embryonic stage 16 and occurred during the tail bud stages,

just as it did in control embryos.

\section{Tail bud stages up to hatching stages}

This period encompasses stages 22 to $34 / 36$.

Morphological aspects. Under microgravity conditions, the closure of the neural tube was completed at stage 31 but was abnormal at the cephalic level. Moreover, 25.4\%, $18.5 \%$ and 9.4 $\%$ respectively of the $\mu \mathrm{G}-$ and $1 \mathrm{G}$ centrifuged and 1G-ground embryos had a small head. The differences were not statistically significant between $\mu \mathrm{G}$ - or 1G-centrifuge $\left(\chi_{c}^{2} 0.450\right)$ or $1 \mathrm{G}$-ground embryos $\left(\chi_{c}^{2} 2.475\right)$ and also between $1 \mathrm{G}$-centrifuge and $1 \mathrm{G}$-ground embryos $\left(\chi_{\mathrm{c}}^{2} 0.674\right)$. As the $\mu \mathrm{G}-, 1 \mathrm{G}$-centrifuge and $1 \mathrm{G}$-ground embryos were fixed during the experiments, their subsequent development could not be followed. However, of the 16 fertilized eggs put in the video-recording box, $14(87.5 \%)$ reached the hatching stage just before the end of the space flight. Two neurulae were abnormal and became abortive tail bud embryos.

The development of cardiac ascites in Pleurodeles embryos was used as an indicator of poor rearing conditions. There were no statistically significant differences between $\mu \mathrm{G}$-, $1 \mathrm{G}$-centriguge and $1 \mathrm{G}$-ground embryos $\left(\chi_{\mathrm{c}}^{2} 0.075\right.$; $2.70 ; 0.579)$ in the frequency of the appearance of ascites. At stages 24 to 32 (Fig. 1J, K), histological analysis indicated no differences between $\mu \mathrm{G}$ embryos and $1 \mathrm{G}$-centrifuged embryos in the central nervous system (CNS), eyes and ears, or in the morphology of the 
head and trunk (Fig. 2B, C). Five hours after landing, six living $\mu \mathrm{G}$-hatched-embryos were fixed. The central nervous system appeared normal. The developing brain subdivisions were structured, and the white matter was located at the periphery of the CNS. Moreover, the differentiation of spinal cord, pronephros and gut were also normal in comparison with $1 \mathrm{G}$-embryos.

At stage 30, the video-recordings showed that the first spontaneous contractions of the trunk musculature occurred in $\mu \mathrm{G}$ - and 1G-ground embryos. At stage 32 , after $180 \pm 3$ hrs of development, the first $\mu \mathrm{G}$-embryos hatched even though the 1G-ground embryos hatched after $230 \pm 3 \mathrm{hrs}$, at stage 33b. At stages 33/34, 10 hours after landing, the young- $\mu \mathrm{G}$ larvae observed with binocular microscope and video-recording displayed swimming behavior identical to that of controls, with no looping or somersaulting. Except for the hatching event, the timing of the embryonic development was the same for $\mu \mathrm{G}$ - and $1 \mathrm{G}$-young larvae.

Immunolocalizations. GABA is an inhibitory transmitter in the CNS. Between stages 26 and 31, no cells stained for GABA were observed in $\mu \mathrm{G}$ - or in $1 \mathrm{G}$-ground embryos, whereas at stages 33 and 34 marked cells were observed both in $\mu \mathrm{G}$ - and in 1G-embryos. In 1G-ground embryos, GABA was first detected at stage 32b-33. The labelled cells were located in the periphery of the spinal cord, in white matter and in cellular aggregates (6-10 cells) in the neural tube and in retinal neurons. GFAP immunolocalization was performed on 6 embryos at stages 28 to 34 . In the spinal cord and at the cephalic level, the radial glia differentiated with an identical time-course in $\mu \mathrm{G}$ - and $1 \mathrm{G}$-ground embryos. The radial extensions were located throughout the neural tube except in its dorsal and ventral walls. The glial buds were normally located and timed (Fig. 2D to F). Astrocytes visualized with anti-GFAP were distributed normally in the differentiating retina in all cases. Using anti-NC1 and phase-contrast microscopy, cell bodies and axons in the diencephalon and in the eyes were seen to be normally located and developed with identical kinetics in $\mu \mathrm{G}$ - and $1 \mathrm{G}$-centrifuge embryos (Fig. 2B and C). Anti-MF20 revealed no delay or positional abnormality in the differentiation of the somites. At stage 32 , organized striated myofibrils appeared with normal chronology in the ventral region of the somite (Fig. 2G).

ChAT activity. This enzyme is involved in the biosynthesis of acetylcholine, the neurotransmitter of cholinergic synapses in the CNS and PNS, and of neuromuscular junctions. ChAT displayed the same activity at stages $32 \mathrm{~b}^{+}$and $33 \mathrm{~b}^{+}$in $\mu \mathrm{G}$-embryos $(\mathrm{N}=5$ and 3$)$ and in $1 \mathrm{G}$-ground controls ( $\mathrm{N}=9$ and 8$)$. In control embryos, ChAT activity was first detectable at stage 31 ; it increased up to stage 34 and remained constant thereafter until stage $36(\mathrm{~N}=4-5$ embryos per stage) (Fig. 3).

\section{Discussion}

The percentages of development of the embryos on board Mir and on earth were weak for the Cassiopeia mission and normal in the case of the Pegasus mission

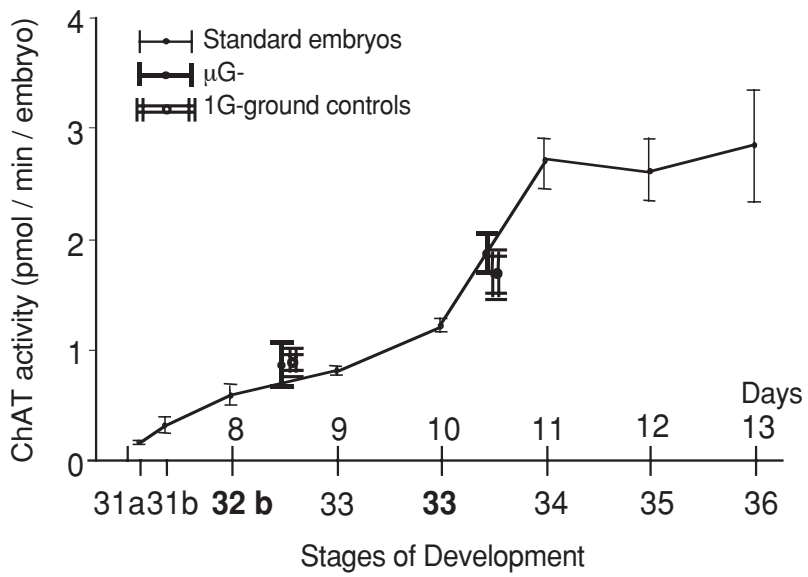

Fig. 3 Choline acetyltransferase activity during the development of standard embryos and at stages $32 \mathrm{~b}^{+}$and $33 \mathrm{~b}^{+}$in $\mu \mathrm{G}$ - and $1 \mathrm{G}$-ground control embryos. At these stages, the differences are not significant (MannWhitney test).

(Table 1). Nevertheless, these were consistent with the preparation of females for the space flights and with the seasons at which the two space missions occurred. On the other hand, it must be pointed out that they was no significant difference in development between our two kinds of controls: the on board 1G-centrifuge and $1 \mathrm{G}$ ground embryos (Table 2).

At the beginning of cleavage, microgravity had effects on embryos. In the animal hemisphere, the standard distribution of the cortical cytoplasm including pigment granules was disturbed for $34.4 \%$ of $\mu \mathrm{G}$-embryos and cleavages were irregular for $31.6 \%$. The data revealed a significant difference between $\mu \mathrm{G}$ - and $1 \mathrm{G}$-ground embryos, but surprisingly, no significant difference between $\mu \mathrm{G}-$ and $1 \mathrm{G}-\mathrm{centrifuge}$ Mir embryos. It must be pointed out that all on board embryos were obtained from eggs oviposited in microgravity, because the cosmonaut randomly placed the fertilized eggs in the centrifuge 1-4 hrs after laying. Consequently, microgravity was able to act on the eggs before the first cleavage (5-6 hrs) explaining, for both alterations in pigmented area and cleavage, the absence of statistical difference between $\mu \mathrm{G}$ - and $1 \mathrm{G}$ centrifuged Mir embryos. In Pleurodeles, Aimar et al (2000) demonstrated that gravitational forces modify the cell membrane of fertilized eggs. We hypothesize that such a phenomenon also occurs during subsequent development, thereby explaining the abnormalities observed in embryos oviposited in microgravity. Another hypothesis could be proposed. As no significant differences of abnormal pigmentation and irregular cleavage between $\mu \mathrm{G}$ - and $1 \mathrm{G}$ embryos on board Mir, and significant differences were observed between $\mu \mathrm{G}$-embryos on board Mir and $1 \mathrm{G}$ embryos on earth, these results could suggest that some abnormalities observed were possibly caused by on board environments rather than by simple environmental factors.

In Pleurodeles, $31.6 \%$ of $\mu \mathrm{G}$-embryos displayed irregular cleavage. In Xenopus, Souza et al. (1995) indicated that under microgravity conditions, the cleavage 
furrow was positioned normally at the two-cell stage, but the mitotic asters showed a slight displacement toward the vegetal pole. Using a clinostat on the ground to simulate microgravity, Neff et al. (1993) and Yokota et al. (1994) observed that the third cleavage shifted toward the embryo equator. Consequently, microgravity has effects on embryos of both Xenopus and Pleurodeles at the beginning of cleavage.

In spite of some asymmetrical segmentations in Pleurodeles, all the $\mu \mathrm{G}$-embryos subsequently acquired normal bilateral symmetry. Consequently, as for Cynops pyrrhogaster, the egg rotation that occurs on earth after fertilization is clearly not necessary in urodeles to determine the position of symmetrical plan (Yamashita et al. 2001). This result supports previous ones for fish in which gravity was shown not to be necessary for the dorsal/ventral axis orientation or subsequent development (Wacker et al. 1993; Ijiri 1995, 1997). It also agrees with previous studies in anurans (Black et al. 1996; Souza et al. 1995; Ubbels et al. 1989, 1994), in which sperm impact induces bilateral symmetry. However, this phenomenon cannot be involved in Pleurodeles, where fertilization is polyspermic.

During cleavage, the intercellular space was significantly enlarged in $40.4 \%$ of $\mu \mathrm{G}$-embryos. This morphological aspect, which could be interpreted by a decrease in cell adhesion, was also observed at the beginning of gastrulation and during neurulation.

At the beginning of gastrulation in Pleurodeles, the blastocoel roof of $1 \mathrm{G}$-embryos normally decreases in thickness. In contrast, the blastocoel roof of $\mu \mathrm{G}$-embryos remained thick, like at late the blastula stage. The thickness of the $\mu \mathrm{G}$-embryo roof was related to a reduction of adhesion between ectodermal cells and not to an increase of the number of cell layers, as observed by Ubbels et al. (1994) for $\mu \mathrm{G}$-embryos of Xenopus laevis or with cell proliferation as proposed by Black et al. (1996). However, the data of Neff et al. (1993) who used a clinostat suggested that the thickening of the blastocoel roof of Xenopus embryos was due to a change in the latitude of the third cleavage plane rather than a modification of cell proliferation. Moreover, De Maziére et al. (1996) observed in $\mu \mathrm{G}$-Xenopus that the blastocoel shifted toward the vegetal hemisphere. The difference between frogs and salamanders could be due to modifications of osmoregulation and volume of the blastocoel liquid (Ubbels et al. 1997).

During gastrulation in Pleurodeles, only young gastrulae were fixed in flight, and consequently, insufficient histological information was obtained on this important embryonic period. Two days after fertilization, organogenesis began with neurulation. Cell adhesion was also perturbed in $\mu \mathrm{G}$-embryos and cells detached. The cellular morphogenetic movements of the forming neural tube occurred more slowly in $\mu \mathrm{G}$-embryos than in $1 \mathrm{G}$ controls and standard embryos. In contrast, epidermis differentiated normally in these embryos. A weakening of the neurectodermal cell junctions could cause a difference in cell adhesion, even if the ectoderm and epidermal cells acquired functional specific junctions, in time. At stage 16, resulting from a ciliary beating movement, the $\mu \mathrm{G}$-embryos began to turn inside their fertilization membrane in the same way as in $1 \mathrm{G}$-control embryos.

During the organogenesis that leads to hatching, although numerous tail-bud embryos appeared with a small head, the statistical differences between the percentages were not significant. Moreover, the percentage of development indicated that these embryos continued their development normally. This was confirmed by videomovies. Of the 16 developing $\mu \mathrm{G}$-embryos, only two abnormal neurulae became abortive tail bud embryos. All the other embryos developed or regulated.

During organogenesis, the immunohistochemical analyses indicated no gross differences between $\mu \mathrm{G}$ - and $1 \mathrm{G}$-embryos in the structural differentiation of organs such as the nervous system. These data are in accordance with previous results obtained during a 12-day space flight. Cultured in vitro, isolated neurectodermal and mesodermal cells differentiated in a normal manner into neurons, glial and muscle cells (Husson et al. 1997). Moreover, the spontaneous muscle contractions occurring before the hatching period and the swimming motor reflexes performed by the first mature neural circuit appeared at the same time in $\mu \mathrm{G}$-embryos and $1 \mathrm{G}$-controls.

On earth, the mean annual dose of received solar and cosmic radiations is about $150 \mathrm{mrad}$ a year, and the admitted human $50 \%$ lethal dose is $450 \mathrm{rad}$. On the ground, the atmosphere protects life from most of the cosmic radiations, but on board a space station, the crew and the living material received all the radiations. During both space flights, the dose received was 30-35 time high than on the ground. The duration of development at $18^{\circ} \mathrm{C}$, from egg laying up to the hatching, was comparable on board the space station and in the ground laboratory. During their further development up to adulthood and reproduction, no abnormality distinguished these animals from standard ones (Dournon et al. 2001). Consequently, it appears that the cosmic radiations did not perturb the development of the animals. This finding agrees with the absence of a significant difference between on board $1 \mathrm{G}$-centrifuge and 1G-ground embryos (Table 2).

The present ontogenetic study in microgravity extends the results obtained with the anuran Xenopus (Ubbels et al. 1989, 1994; Souza et al. 1995; Black et al., 1996) and the fish Medaka (Ijiri 1995, 1997). In Pleurodeles, the observed abnormalities, cortical cytoplasm movements, decrease of cell adhesion and loss of cells, probably concern the cell membrane, as suggested by the results of Schatz et al. (1990), Claassen et al. (1996) and Aimar et al. (2000). Modifications or alterations of physico-chemical properties of the membrane could involve the cytoskeleton (Spooner et al. 1994; Tabony 1994; Lewis et al. 1998). It will be interesting to determine whether abnormalities involve modifications of cell membrane or cell junctions.

In conclusion, the data confirm that microgravity conditions have effects during the embryonic period and particularly during cleavage and neurulation of amphibians. 
Although the early development was not strictly normal, as a consequence of embryological regulation phenomena, the young hatching larvae had a normal morphological aspect and swimming behavior after landing. Video-movies performed on board Mir clearly confirm this point.

\section{Acknowledgments}

We would like to thank Françoise Foulquier and Julian Smith from the Developmental Biology Center in Toulouse and Christiane Tankosic from the Experimental Biology-Immunology Laboratory in Nancy for technical assistance. We gratefully acknowledge all the CNES board and particularly Didier Chaput and Michel Viso, for engineering and management. We have the great pleasure to thank the French cosmonauts Dr. Claudie AndréDeshays and Lieutenant Colonel Léopold Eyhartz for efficient practical expertise. We are grateful to our Russian colleagues and particularly the RKK Energia ones for preparation and success of the space missions. This work was supported by grants of the French space agency, the Centre National d'Etudes Spatiales.

\section{References}

Aimar, C., Bautz, A., Durand, D., Membre, H., Chardard, D., Gualandris-Parisot, L., Husson, D. \& Dournon, C. (2000) Microgravity and hypergravity effects on fertilization of the salamander. Biol. Reprod., 63, 551-558.

Black, S., Larkin, K., Jacqmotte, N., Wassersug, R., Pronych, S. \& Souza, K. (1996) Regulative development of Xenopus laevis in microgravity. Adv. Space Res., 17, 209-217.

Claassen, D.E; \& Spooner, B.S. (1996) Liposome formation in microgravity. Adv. Space Res., 17, 151-160.

De Maziéres, A., Gonzales-Jurado, J., Reijnen, M., Narraway, J. \& Ubbels, G.A. (1996) Transient effects of microgravity on early embryos of Xenopus laevis. Adv. Space Res., 17, 219223.

Dournon, C., Durand, D., Tankosic, C., Membre, H., GualandrisParisot, L. \& Bautz, A. (2001) Effects of microgravity on the larval development, metamorphosis and reproduction of the urodele amphibian Pleurodeles waltl. Dev. Growth Differ., 43, 315-326.

Duprat, A.M., Kan, P., Gualandris, L., Foulquier, F., Marty, J. \& Weber, M. (1985) Neural induction: embryonic determination elicits full expression of specific neuronal traits. J. Embryol. Exp. Morph., 89, 167-183.

Gallien, L. \& Durocher, M. (1957) Table chronologique du dÈveloppement chez Pleurodeles walttii Michah. Bull. Biol. Fr. Belg., 91, 97-114.

Husson, D., Chaput, D., Bautz, A., Davet, J., Durand, D., Dournon, C., Duprat, A.M. \& Gualandris-Parisot, L. (2001) Design of specific hardware to obtain embryos and maintain adult urodele amphibians aboard a space station. Adv. Space Res., 27, 433445.

Husson, D., Gualandris-Parisot, L., Foulquier, F., Grinfeld, S., Kan, P. \& Duprat, A.M. (1997) Differentiation in microgravity of neural and muscle cells of a vertebrate (amphibian). $A d v$. Space Res., 22, 303-308.

Ijiri, K. (1995) The first vertebrate mating in space: A fish story. Ricut (ed.), Tokyo, Japan, 57p.

Ijiri, K. (1997) Explanations for a video version of the first vertebrate mating in space - a fish story. Biol. Sci. Space, 11, 153-167.

Lewis, M.L., Reynolds, J.L., Cubano, L.A., Hatton, J.P., Lawless, B.D. \& Piepmeier E.H. (1998) Spaceflight alters microtubules and increases apoptosis in human lymphocytes (Jurkat). FASEB $J ., 12,1007-1018$.

Mogami, Y., Imamizo, M., Yamashita, M., Izumi-Kurotani, A., Wiederhold, M.L., Koike, H. \& Asashima, M. (1996) Astronewt: early development of newt in space. Adv. Space Res., 17, 257-263.

Neff, A.W., Yokata, H., Chung, H.M., Wakahara, M. \& Malacinski, G.M. (1993) Early amphibian morphogenesis is sensitive to novel gravitational fields. Dev. Biol., 155, 270274.

Pituello, F., Kan, P., Geffard, M. \& Duprat, A.M. (1989) Initial GABAergic expression in embryonic amphibian neuroblasts after neural induction. Int. J. Dev. Biol., 33, 445-453.

Saint-Jeannet, J.P., Huang, S. \& Duprat, A.M. (1990) Modulation of neural commitment by changes in target cell contacts in Pleurodeles waltl. Dev. Biol., 141, 93-103.

Schatz, A., Reitstetter, R., Linke-Hommes, A. \& Briegleb, W. (1990) Gravity perception by non specialized structures. ESA SP, 307, 313-314.

Souza, K.A., Black, S.D. \& Wassersug, R.J. (1995) Amphibian development in the virtual absence of gravity. Proc. Natl. Acad. Sci. U.S.A., 92, 1975-1978.

Spooner, B.S., Hardman, P. \& Paulsen, A. (1994) Gravity in mammalian organ development: differentiation of cultured lung and pancreas rudiments during spaceflight. J. Exp. Zool., 269, 212-222.

Tabony, J. (1994) Morphological bifurcations involving reactiondiffusion processes during microtubule formation. Science, 264, 245-248.

Ubbels, G.A. (1997) Establishment of polarities in the oocyte of Xenopus laevis: the provisional axial symmetry of the fullgrown oocyte of Xenopus laevis. Cell Mol. Life Sciences, 53, 382-409.

Ubbels, G.A., Berendsen, W. \& Narraway, J. (1989) Fertilization of frog eggs on a sounding rocket in space. Adv. Space Res., 9, 187-197.

Ubbels, G.A., Reijnen, M., Meijerink, J. \& Narraway, J. (1994) Xenopus laevis embryos can establish their spatial bilateral symmetrical body pattern without gravity. Adv. Space Res., 14, 257-269.

Wacker, S., Herrmann, K. \& Berking, S. (1993) The orientation of the dorsal/ventral axis of zebrafish is influenced by gravitation. Roux's Achives, 203, 281-283.

Yamashita, M., Izumi-Kurotani, A., Imamizo, M., Koike, H., Okuno, M., Pfeiffer, C.J., Komazaki, S., Sasaki, F., Ohira, Y., Kashima, I., Kikuyama, S., Ohnishi, T., Mogami, Y. \& Asashima. M. (2001) Japanese Red-Bellied Newts in Space AstroNewt Experiment on Space Shuttle IML-2 and Space Flyer Unit. Biol. Sci. Space., 15 (Suppl), 96-103.

Yokota, H., Neff, A.W. \& Malacinski, G.M. (1994) Early development of Xenopus embryos in affected by simulated gravity. Adv. Space Res., 14, 249-255.

Young, R.S. \& Tremor, J.W. (1968) The effect of weightlessness on the dividing egg of Rana pipiens. Bioscience, 18, 609-615. 